This is the peer reviewed version of the following article: Menzies,, K. and Johnson, F. Academic Attitudes toward New Media: an Exploratory multidisciplinary Study." The Information Society 32(1), $2016 \mathrm{pp} 1-13$, which has been published in final form and available at http://www.tandfonline.com/doi/full/10.1080/01972.

\title{
Academic Attitudes toward New Media: An Exploratory Multi- Disciplinary Study
}

Kathleen Menzies and Frances Johnson, Department of Information and Communications, Manchester Metropolitan University, Manchester, United Kingdom

Corresponding author: Dr. Frances Johnson, Department of Information and Communications, The Faculty of Humanities, Languages and Social Science, Manchester Metropolitan University, Geoffrey Manton Building, Rosamond Street West, Manchester M15 6LL. Email: F.Johnson@mmu.ac.uk

Keywords: new media, academics, attitudes, higher education, digital technology, semantic differentials Running head: Academic Attitudes toward New Media

\begin{abstract}
This paper looks at the attitudes of UK academics toward new media, utilising organisational and sociocultural understandings of fields of scholarly enquiry. It focuses on four traditionally distinct disciplinesCreative Arts and Design, Computer Science, Health Science, Politics and International Relationsrepresentative of the range of approaches in higher education. Agreement was found among respondents across disciplinary communities about what new media represent and how they support their work.
\end{abstract}


Analysis of semantic differential charts identified two dimensions underlying attitudes_-'Flexibility' and 'Fitness for Scholarly Purposes'. Rather than being anchored by epistemological divisions, new media are assessed by practical viewpoints relating to the activity types they allow, and traditional measures of reliability. 


\section{Introduction}

Studies of adoption and use of new media by academics typically focus on use, behaviour, and instrumentalization of these technologies, which complement or alter the existing research and teaching modalities. This paper addresses a gap by exploring attitude — specifically, attitudes of academics in the UK toward contemporary new media (broadly defined as many-to-many online communication services and digital multimedia objects) and the degree to which they are influenced by their home disciplines.

Academic disciplines possess cultural and social characteristics that allow us to discriminate between them and position them in relation to one another (Abbott, 1999; Whitley, 2000). They are manifested in the acceptance and use of certain theories, genres and analytical methods, the procedures and channels for validating and sharing work, and the types of audiences for which the work is intended (Foucault, 1966; Gläser et al., 2010; Nystrand, 1982; Whitley, 2000). Even when generalities are enforced across fieldsmost recently, in many universities, because of changes to the ways in which research is pursued and assessed — field specific manifestations are discernable (Gläser et al., 2011). This does not imply that discipline characteristics are entirely fixed. The "formative context" in which a work is developed may not be the one in which audiences interpret them-for example, empirical work may be treated rhetorically or have "rhetorical effects" (Nystrand, 2001, p. 94). Unexpected outcomes like these enable new alliances between "disciplinary insiders" and practitioners working in other areas, potentially cutting across entrenched methodological and "institutional divisions" (Miller, 2001). This may happen more readily at the "fringes" of a discipline (Miller, 2001) than at its "core", toward which new approaches are generally "forced back" (Abbott, 1999, p. 149).

Nowotny et. al (2002) argue that "near absolute demarcation criteria" have "failed" within universitiesscience being a case in point. Even when its practitioners, acting on a desire for "institutional protection" and self-preservation, insist that their epistemological core is distinct, boundaries between academic subsystems are now too porous to justify such a view. Academia has moved beyond certainties of "disciplinary territories" (Trowler, 2009) to multi-modal, interdisciplinary and cross-sectoral forms of study and research as well as to fragmentation - even within single disciplines, where consensus over methods and styles is no longer the norm (Lattuca, 2001). Weller (2010), discussing "digital, networked and open" approaches to technology observes that while the individual factors at play in how academics 
relate to these changes may represent "simply an adjustment to existing practise", the impact of each"when considered across the whole community"—is potentially "revolutionary", reflecting the "somewhat schizophrenic nature of digital scholarship at the current time" (p. 9). Emerging or fluid organisational and epistemological patterns incorporate subjective and agent-specific factors and assumptions in ways that are different from the past (Trowler, 2006). In effect, new media and digital technology can be seen as both emblematic and symptomatic of changes which may be understood as rearrangements, or as moments of "revolution" (Lanham, 1993; Kuhn 1996; Manovich, 2001; Agre in Dutton and Loader, 2002; Nowotny et al., 2002; Kress, 2005; Cunningham, Clements and Cunningham, 2012).

Nowotny et al. (2002) talk of Mode 1 (old modalities) and Mode 2 (new modalities) academia. In their conception, Mode 2 is typified by, among other things, "socially distributed expertise", and "changing rules of engagement" whereby professional relationships become "vertical" rather than "horizontal" and where traditional modes of interaction are "aided" and altered by "the pervasive role" of new media (p. 105). It incorporates multiple views and perspectives, including audiences outside the academy. Mode 2 is thus "more dialogic" than Mode 1. " Exploring this hypothesis, Heimeriks et al. (2008) argue for a more nuanced and less radical perspective, as typological discipline characteristics persist regardless of disruption or interdisciplinarity for various reasons. They provide an administrative and analytical utility which is vital to how most European and American universities are organised, how they function, how they contribute to public discourse, how they "reproduce" their internal logic (Bourdieu, 1988, p. 15) and how they maintain "the relative separation of disciplinary cultural lineages" (Abbott, 1999, p. 148).

While new media may catalyse methodological innovations and contribute to genuine transformation, this does not preclude them being used in ways that mimic, supplement or reinforce extant patterns of thought, organisation, style, and behaviour. Anything new, or labelled 'new', is dependent upon conditions of time, space, and the characteristics of society/societies at a given historical moment. As Manovich demonstrates, the "most substantial consequence of media's computerization" arises from their "cultural reconceptualizations"-i.e. the processes that give rise to a "conceptual transfer from [the] computer world to culture at large" (2001, page 65) - yet this may be more gradual and subtle than a sudden revolution. New tools do not always lead to new socio-cultural or epistemic modes. Many of new media's supposedly 'novel' cultural and technical characteristics (e.g. interactivity and multimedia display) were present in 
previous technologies. Pre-existing structures, priorities and attitudes lead particular groups or individuals to understand and use new media in different ways. Analytically, this is useful, because technologies and their users can be seen to exist within "information ecologies" (Nardi and O'Day, 1999) or communities (Smith and Kollok, 1999) which possess particular and relatively distinct characteristics, although naturally there may be overlaps and concurrences between them. At the same time, new technologies lead to new forms of production which in turn influence social and individual consciousness (cf. Marx, 1859). In effect, new media are dependent upon multiple systems of representation and exchange for the attribution of meaning and value. Structures of governance, pedagogy, knowledge production and consumption intersect with the semiotics of language and culture to affect how they are positioned and perceived. When they proliferate and become increasingly "ubiquitous" (Greenfield, 2006), they accrue further positions and values and engender new methods for use and interpretation. As parts of an everexpanding discursive network wherein the cognitive and social are bound up with both deliberately designed and unintended consequences, the meanings and impacts of technologies are difficult to discern.

Utilising organisational and socio-cultural understandings of discipline, we studied attitudes of academics in four traditionally distinct areas of scholarly enquiry_-Art and Design, Computer Science, Health Science, and Politics and International Relations. Drawing on Whitley's organisational model of the sciences (Whitley, 2000) these are, as a group, representative of the variance that exists within academia hence. That enabled us to assess the relevance of discipline to understandings of new media. Mindful of the above-discussed persisting and changing character of disciplines and Dervin's (2003) notion of "communicatings," we sought to understand the relationship between attitudes of academics and their disciplinary homes in all its complexities.

\section{Methods and data gathering}

Symbolic mental processes and social behaviours are intrinsically linked. Attitudes guide the behaviours that create and maintain "social structures and systems" (Forgras, Cooper and Crano, 2011), in a complex interplay with material and socio-economic factors, which themselves influence attitudes. Similarly, learning, affected by attitudes toward whatever is being learned, "cannot be separated from its sociocultural context" (Ornek 2011, page 241). Individuals engaging with technologies and media are never 
isolated. Activities are embedded in particular socio-cultural and socio-technical systems comprising a series of multi-layered processes involving mediated artefacts, group behaviours or norms, and individual cognition (Lave and Wenger, 1991; Nardi and O'Day 1999; Egenström 2002; Cook and Yanow, 2006). The primary data gathering tool selected and constructed for empirical research was a semantic differential chart, a technique for attitude measurement derived from clinical psychiatry. These comprise a bi-polar numeric interval scale with potentially opposing adjectives positioned at either end. Supporting both qualitative and quantitative analysis, semantic differentials give respondents an opportunity to convey subtle and (potentially) multi-dimensional attitudinal perspectives. From an original dataset, contrasts and correlations between attitudes toward new media within and across disciplines were captured and analysed. Supplementing this, a series of questions — using a simpler Likert scale of agreement—were also posed, allowing the analysis of academics' attitudes toward their particular discipline; i.e. its organisation, culture, work methods and tooling. These instruments were informed by a review of literature on new media from multiple fields-Information Science, Politics, Philosophy, Organisational Studies, Business Studies, and Media and Cultural Studies. Methods and analysis are described below.

\subsection{Sampling Technique}

To gain a purposive but representative sample from across disciplines, a sampling frame based upon Whitley's typology of the sciences (Whitley, 2000) was employed. This classifies and positions both the super- and sub-fields of science (which includes the social sciences) in relation to one another along certain proposed dimensions. Two master variables—-mutual dependence and task uncertainty—sub-divide onto two axes: mutual dependence contains functional dependence and strategic dependence; task uncertainty contains technical uncertainty and strategic uncertainty. Disciplines are assigned generalised positions at the high or low ends of these axes. They can therefore be ordered according to their location in each dimensional space, allowing organisational and reputational characteristics to be studied in relation to one another. By sampling strategically and purposively within these dimensions, disciplines with diverse characteristics from relatively distinct positions were identified and selected as targets for data gathering. ${ }^{1}$

\footnotetext{
${ }^{1}$ This strategy is based on the work of Fry and Talja (2007), who extrapolated from Whitley's variables to categorise academic "case studies in relation to one another based on the presence of [a range of] qualitative
} 
Whitley also proposes categories that describe organisational structures and contextual aspects of disciplines such as the extent of hierarchical organisation, formality of control, extent of conflict, performance standards, and audience composition. Some disciplines are classified as "fragmented adhocracies" with a diverse audience and which may "have some difficulties in excluding amateurs" from making competent contributions; these are positioned in contrast to "conceptually integrated bureaucracies", typified by high levels of task certainty and strict rules of governance (pp. 159-161). The former fields are those which are low in functional dependence and high in task uncertainty and the latter, the reverse. These categories have been tested, employed, and found to be analytically valid means by which to explore the dynamic compositions and structures that typify processes and patterns of innovation and control within universities (Braun, 2011; Engwall, 1996; Knudsen, 2011, Engwall and Danell, 2011). The four disciplines considered by this research can be broadly classified as shown in Table 1 below. Please note that positions assigned are not absolute; further, they reflect the authors' interpretation of the work of Whitley, and Fry and Talja's extension of his models to include humanities subjects.

Table 1 - The academic subjects chosen for data gathering and analysis, classified using a modified version of Whitley's typology.

\begin{tabular}{|c|c|c|}
\hline $\begin{array}{l}\text { Positions on Mutual Dependence } \\
\text { (Functional and Strategic } \\
\text { Dependence) and Task Uncertainty } \\
\text { (Technical task and Strategic task } \\
\text { uncertainty) axes. }\end{array}$ & Field & $\begin{array}{l}\text { Organisational } \\
\text { Characteristics }\end{array}$ \\
\hline $\begin{array}{l}\text { Low/Low } \\
\text { High/High }\end{array}$ & Creative Arts and Design & $\begin{array}{l}\text { Most closely resembles a } \\
\text { Fragmented adhocracy; to } \\
\text { some extent Unstable }\end{array}$ \\
\hline $\begin{array}{l}\text { High/High } \\
\text { Medium/Medium }\end{array}$ & Computer Science & $\begin{array}{l}\text { Most closely resembles a } \\
\text { Professional adhocracy; } \\
\text { elements of a Polycentric } \\
\text { profession }\end{array}$ \\
\hline $\begin{array}{l}\text { High/Low } \\
\text { Low/Low }\end{array}$ & $\begin{array}{l}\text { Health Science (including } \\
\text { Dentistry, Medicine, Sports } \\
\text { Science, Healthcare } \\
\text { Sciences, Nursing and } \\
\text { Midwifery) }\end{array}$ & $\begin{array}{l}\text { Most closely resembles a } \\
\text { Technologically } \\
\text { integrated bureaucracy }\end{array}$ \\
\hline $\begin{array}{l}\text { Low/Medium } \\
\text { Medium/High }\end{array}$ & $\begin{array}{l}\text { Politics and International } \\
\text { Relations }\end{array}$ & $\begin{array}{l}\text { Combines elements of a } \\
\text { Fragmented adhocracy } \\
\text { and a Partitioned } \\
\text { bureaucracy }\end{array}$ \\
\hline
\end{tabular}

indicators" (p. 8) in their work on academic use of digital resources, extending his typology beyond the sciences to include humanities subjects. 
Although Whitley discusses dependencies between fields in relation to the changing perceptions and management of science and knowledge production over time, he does not directly address interdisciplinarity or the role of ICTs. In light of this, an examination of contemporary attitudes in relation to his work is useful, not least when we consider the relationship between disciplinary rigidity and control, the technical mechanisms used to co-ordinate task outcomes and the extent of "permissible novelty" within a field. Whitley's typology does not necessarily capture the complex dynamics between research and technology or "account well for contemporary multidisciplinary or transdisciplinary alliances"; nevertheless, it provides a coherent and "powerful" way to understand and compare academic fields of enquiry (Talja and Fry, 2000, page 17). Given that fields can be positioned relatively within Whitley's proposed dimensions, "medium" has been included where this reflects a more accurate characterisation of the field under consideration, particularly in comparison to humanities disciplines, which were not originally considered by Whitley.

\subsection{Instruments}

Comprised of bi-polar adjective scales separated by a (usually numerical) interval of measurement, semantic differentials provide a way to assess and measure attitude and connotative meaning through ranking and factor analysis. Participants are asked to position a concept (or stimuli) on an interval scale in relation to a pair of opposing adjectives, allowing researchers to identify where those terms are located in various distinct "dimensions" within a respondent's cognitive space. These can be used to understand and highlight the "attitudinal variation and flux" which probably "contributes to variations in behavior" at an individual level (Heise, 1970, p. 250). With a large enough dataset, these can also be used to study "cultural and group differences" and "shifts and distortions of basic attitudinal structure[s]" across groups. In general, the validity and reliability of semantic differential scales are satisfactory, with "correlation coefficients of approximately .80 between the semantic differential ratings and Thurstone, Likert, and Guttman scales" PAGE NUMBER ?? and test-retest reliability of about .90 (Key, 2007). The 0 indicates a balanced midway point where the stimuli is perceived to be as much typified by the first term in the pair as the second. This leaves room for acknowledgement of the nuances involved in constructing real or 
apparent polar 'opposites'. The 12 pairs of semantic differentials selected are described in Table 2 below.

The results of subsequent analysis and reliability testing are then discussed.

Table 2 - The semantic differential pairs used for data gathering

In my view, new media are, in nature...

\begin{tabular}{l|rrrrrrr|r}
\hline Private & 3 & 2 & 1 & 0 & 1 & 2 & 3 & Public \\
\hline Elitist & 3 & 2 & 1 & 0 & 1 & 2 & 3 & Egalitarian \\
\hline Deliberative & 3 & 2 & 1 & 0 & 1 & 2 & 3 & Participative \\
\hline Fixed & 3 & 2 & 1 & 0 & 1 & 2 & 3 & Fluid \\
\hline Emergent & 3 & 2 & 1 & 0 & 1 & 2 & 3 & Pre-defined \\
\hline Inclusive & 3 & 2 & 1 & 0 & 1 & 2 & 3 & Exclusive \\
\hline Objective & 3 & 2 & 1 & 0 & 1 & 2 & 3 & Subjective \\
\hline Faddish & 3 & 2 & 1 & 0 & 1 & 2 & 3 & Grounded \\
\hline Deep & 3 & 2 & 1 & 0 & 1 & 2 & 3 & Shallow \\
\hline Passive & 3 & 2 & 1 & 0 & 1 & 2 & 3 & Active \\
\hline Social & 3 & 2 & 1 & 0 & 1 & 2 & 3 & Isolating \\
\hline Reliable & 3 & 2 & 1 & 0 & 1 & 2 & 3 & Unreliable
\end{tabular}

The terms in the semantic differential pairs were identified through a wide-ranging literature review that included texts from multiple disciplines. Their selection was also informed by a pilot data gathering exercise involving discussions and interviews with 8 participants from the 4 chosen fields. For the purposes of expediency, the generic category of "new media" was selected as the stimulus that would be rated in relation to these. Many semantic differential scales use adjective pairs which can be simplistically understood as 'negative' or positive' (such as 'good-bad' or 'clean-dirty'). This makes it easier to conduct statistical analyses and to assess scale reliability; i.e. to find a correlation between responses to items that suggest the same underlying construct is being measured. To do this, terms positioned in reverse to avoid response bias must first be 'corrected'. Naturally, terms and constructs cannot always be so clearly divided, and this may be problematic. To proceed with analysis, terms which in the context of new media are generally considered negative (for instance, "elitist" and "faddish") were reversed from their 'positive' position on the instrument given to respondents (used to avoid response bias). The Cronbach alpha values obtained for scale reliability were acceptable but rather low (.719). This is likely attributable to the complexity of the stimulus and constructs (scale items) used. Six pairs using rather more complex 
terminology were removed entirely as their corrected item total correlation values were too low (less than .3), compromising the scale's utility. These are shown in Table 3.

Table 3 - complex terms removed from the semantic differentials to improve scale reliability

\begin{tabular}{l|rrrrrrr|r} 
Immaterial & 3 & 2 & 1 & 0 & 1 & 2 & 3 & Material \\
\hline Time-biased & 3 & 2 & 1 & 0 & 1 & 2 & 3 & Space-biased \\
\hline Procedural & 3 & 2 & 1 & 0 & 1 & 2 & 3 & Exploratory \\
\hline Work-biased & 3 & 2 & 1 & 0 & 1 & 2 & 3 & Play-biased \\
\hline Tactile & 3 & 2 & 1 & 0 & 1 & 2 & 3 & Virtual \\
\hline $\begin{array}{l}\text { Socially-constructed } \\
\text { knowledge }\end{array}$ & 3 & 2 & 1 & 0 & 1 & 2 & 3 & Individually-constructed \\
knowledge
\end{tabular}

\subsection{Population and Demographics}

Data on the number of academics working in UK universities by faculty or department are not made publicly available, however using figures provided by the Higher Education Statistics Agency (HESA) on the total number of academics employed in the UK (excluding atypical cases this is 181,385) (Higher Education Statistics Agency, 2013a), the approximate size of the relevant population for this study and thus the approximate confidence level we can have in results based on our sample as generalisable to the wider population was calculated. To have 95 percent confidence and a 5 percent margin of error a sample of 309 participants would be required. ${ }^{2}$ An online version of the semantic differential exercise and questions about discipline were distributed to 953 individuals (240 from Art and Design, 270 from Health Sciences, 188 from Politics and International Relations and 255 from Computer Science) based in 112 Universities (and constituent colleges) in the UK. They were also asked to forward the request for participation to other colleagues. Mailing lists were constructed manually by visiting the websites of all UK universities. A response rate of approximately 22 percent (209 responses) was achieved. This allows us 95 percent confidence but with a 6.76 percent margin of error. Respondents can be categorised by discipline as shown in Table 4.

\footnotetext{
${ }^{2}$ The average number of academic departments is (at an estimate) 20. Being interested in 4 specific fields, we can calculate the average number of staff in each to infer (having corrected the total to reflect that only 112 universities were in scope for this study) that the number of academics working in Art and Design, Computer Science, Healthcare Sciences and Politics and International Relations departments combined is around 34,944 .
} 
Other potentially useful demographic information was also collected as shown in Table 5 . The typical respondent to our questionnaire is male, between 41 and 65 years old ${ }^{3}$, has been working in his field for between 11 and 20 years, and uses new media daily for both work and non-work purposes.

Table 4 - Breakdown by discipline of the 209 respondents to the online data gathering exercises

\begin{tabular}{l|l} 
Discipline & Percentage \\
\hline Art and Design & 26.3 \\
\hline Computer Science & 36.4 \\
\hline Healthcare Science & 24.9 \\
\hline Dentistry & 4.3 \\
\hline Medicine & 1.9 \\
\hline Health Science & 18.7 \\
\hline Politics and International Relations & 12.5
\end{tabular}

Table 5 - Demographic details of the 209 respondents to the online data gathering exercises

\begin{tabular}{|c|c|c|c|c|c|c|c|}
\hline \multirow{2}{*}{$\begin{array}{l}\text { Variable } \\
\text { Gender }\end{array}$} & \multicolumn{2}{|c|}{$\begin{array}{l}\text { Category } \\
\text { Percentage }\end{array}$} & & & & & \\
\hline & Female & Male & & & & & \\
\hline Percentage & 35 & 65 & & & & & \\
\hline Age & 25 or less & $26-40$ & $41-65$ & & & & \\
\hline Percentage & 2.4 & 34 & 63.6 & & & & \\
\hline Length in field (years) & $0-1$ & $2-5$ & $6-10$ & $11-20$ & $21-30$ & $31-40$ & $40+$ \\
\hline Percentage & 4.8 & 18.2 & 17.7 & 33.5 & 16.8 & 7.7 & 1.4 \\
\hline $\begin{array}{l}\text { Frequency of new media use } \\
\text { (work) }\end{array}$ & Daily & Weekly & Monthly & Rarely & Never & & \\
\hline Percentage & 49.3 & 19.1 & 9.6 & 15.8 & 6.2 & & \\
\hline $\begin{array}{l}\begin{array}{l}\text { Frequency of new media use } \\
\text { (non-work) }\end{array} \\
\end{array}$ & Daily & Weekly & Monthly & Rarely & Never & & \\
\hline Percentage & 66.8 & 16.4 & 1.9 & 9.6 & 5.3 & & \\
\hline
\end{tabular}

\section{Analysis}

\footnotetext{
${ }^{3}$ This fits broadly with statistics showing UK academics are more likely to be male than female and that as a whole, the academic population is generally middle aged (Higher Education Statistics Agency, 2013b).
} 
The focus of this research is on assessing the extent to which a disciplinary lens can be used to explore, position and categorise attitudes toward new media in academia. The extent to which there is agreement among respondents about the characteristics of their disciplines was explored prior to the analysis of results from semantic differential exercises, which as instruments are more complex. An understanding of how unified those in a field appear to be, and the extent to which disciplinary communities remain distinct, usefully informs our exploration of the attitudinal positions of respondents to new media terms and concepts drawn from multiple generic discourses. Factor analysis - which is not based on disciplineallows us to identify the underlying dimensions that influence and give structure to academics' attitudes across disciplines. Analysis and key findings are presented and discussed below.

\subsection{Agreement on discipline characteristics}

Using a 5 point Likert scale of agreement $(1=$ Strongly Disagree; $2=$ Disagree; $3=$ Neutral $4=$ Agree and 5=Strongly Agree), questions on discipline characteristics were as follows:

1. Keeping up to date with digital technology is generally important in my subject discipline.

2. In my view, keeping up to date with digital technology should be considered more important in my subject discipline.

3. In my subject discipline, there is usually a broad consensus about methods and techniques.

4. Interdisciplinary work is generally important to my subject discipline.

5. The audience that my subject discipline shares its work with is generally varied and diverse.

6. It is important to take part in online social networks with academics working in the same subject discipline as myself.

7. It is important to take part in online social networks with academics from other subject disciplines.

8. In my subject discipline, there is usually a broad consensus about the interpretation and meaning of research results and outputs.

9. In my subject discipline, novelty (of approach, technique, or interpretation) is generally allowed and encouraged.

10. My subject discipline is strongly influenced by what might be called a "reputational elite". 
Each addresses some aspect or characteristic by which disciplines can be relatively positioned; either using measures identified as important by Whitley (Questions 3, 5, 8, 9 and 10) or ones which refer directly to the central concerns of this research - in particular, technology, participation and interdisciplinarity (Q 1, 2, 4, 6, 7). Significance values of less than $.05(.000)$ obtained from a Kolmogorov-Smirnoff test show that the distributions of responses are non-normal. Illustrative statistics show the distribution curves of responses to be largely similar for all groups. Techniques suitable for non-parametric data were used to explore variations between and within groups. A Kruskal-Wallis test allowed us to reject the null hypothesis - that response distributions are the same across disciplines - for 8 out of 10 questions, as shown in Table 6 below. This indicates that the mean ranks of answers are significantly different across the four disciplines, hence differences in distribution are not simply due to chance or the sampling procedure used. Proceeding on the assumption of differences between disciplines is therefore valid.

Post-hoc analysis was required to explore which groups vary significantly and to what extent. A series of Mann Whitney U-tests (the Bonferonni adjustment made to avoid Type 1 errors gave us a $p$ value of .08) showed differences in distribution to be at a statistically significant level in 67.5 percent of the questions showing difference (or 45 percent of all questions). Significance values for all questions showing difference are presented in Table 7 below. Two questions, which are illustrative of our findings from this data, are then discussed.

Table 6 - Significance values from a Kruskal-Wallis Test analysing responses to questions about discipline characteristics. Grouping variable: Discipline.

\begin{tabular}{l|l|l|l|l|l|l|l|l|l|l}
\hline & Q1 & Q2 & Q3 & Q4 & Q5 & Q6 & Q7 & Q8 & Q9 & Q10 \\
\hline Chi-Square & 43.231 & 22.662 & 8.776 & 10.523 & 4.724 & 4.901 & 9.677 & 15.970 & 23.871 & 13.443 \\
\hline df & 3 & 3 & 3 & 3 & 3 & 3 & 3 & 3 & 3 & 3 \\
\hline Asymp. Sig. & .000 & .000 & .032 & .015 & .193 & .179 & .022 & .001 & .000 & .004 \\
\hline
\end{tabular}

Table 7 - Significance values for Mann-Whitney U tests analysing responses to questions about discipline characteristics, grouped by discipline pairs.

\begin{tabular}{l|l|l|l|l|l|l|l|l}
\hline Disciplines & Q1 & Q2 & Q3 & Q4 & Q7 & Q8 & Q9 & Q10 \\
& & & & & & & & \\
\cline { 2 - 7 } & \multicolumn{7}{|c}{$p$ values $<.08$ are significant } \\
\hline Art and Computing & .000 & .071 & .098 & .434 & .010 & .003 & .838 & .002 \\
\hline
\end{tabular}




\begin{tabular}{l|c|c|c|c|c|c|c|c}
\hline Art and Health Science & .331 & .188 & .083 & .665 & .081 & .007 & .001 & .211 \\
\hline Art and Politics & .001 & .001 & .231 & .003 & .012 & .514 & .002 & .673 \\
\hline Computing and Health Sciences & .000 & .003 & .958 & .712 & .466 & .734 & .000 & .053 \\
\hline Computing and Politics & .000 & .000 & .015 & .009 & .693 & .009 & .000 & .001 \\
\hline Health Sciences and Politics & .006 & .019 & .010 & .004 & .326 & .016 & .439 & .116 \\
\hline
\end{tabular}

In response to Question 1, p values suggest statistically significant differences between all groups, with the exception of Art and Design and Health Science (.331). Differences between this pairing were least significant across all questions but were significant for Qs 7 and 8. Discipline can therefore be seen to play a role in influencing responses. We may be able to explain some of the variance between groups by considering the extent to which each discipline is expected to incorporate, or is defined by its relationship to, changing media and technologies; for instance, Computer Science is far more dependent on engaging with these than is Political Science research. That responses from those working in Art and Design and those working in Health Sciences were not significantly different from one another is more intriguing, highlighting the complexity of this research and suggesting some unexpected convergences in disciplinary attitudes toward technologies. The median value for each discipline in response to Q1 was 4.00 (agree), with the exception of Computer Science where it was 5.00 (strongly agree).Overall, 90 percent of respondents agree or strongly agree when asked if keeping up to date with digital technology is important in their field.

In response to Question 10, which deals with reputational control, a less expected picture emerges. $\mathrm{p}$ values here are very different and significance levels are more mixed. $p$ values are: Art and Design and Computer Science (.002), Computer Science and Politics (.001), Health Sciences and Computer Science (.053), Health Sciences and Politics (.116), Art and Design and Health Sciences (.211) and Art and Design and Politics (.673). Some disciplines typically positioned closely in this dimension (such as Health Science and Computing) show more differentiation than those typically positioned further apart (such as Art and Design and Computing). Some of those positioned less closely, show a less significant level of difference (for instance, Art and Design and Politics, or Art and Design and Health Sciences). Again, this is suggestive of a subtle shift in the relative positions of disciplines on Whitley's axes. Most respondents agreed that a reputational elite is influential in their field, with the median value in all groups being 4 . This 
is interesting because it does not follow the pattern suggested in Whitley's classification; for instance, Health Science is traditionally more tightly controlled reputationally than is Politics.

Whitley's writing makes it clear however that the role and influence of reputational elites is complex, changing in relation to various organisational and cultural factors over time. In particular he notes that "the more concentrated is control over the major communication media [of a field] the easier it is for a small elite to set standards and direct research strategies", reducing intellectual pluralism (page 107). A greater engagement with technology than is traditional, may be shifting reputational power structures within Politics and Art and Design more directly than in Health Science, perhaps partly because of its relative novelty there. Further, it is in fields where the diversity of permissible theories and methods is restricted, that reputational rewards are more normative, hierarchical and predictable and hence, where elites have been historically more visible and influential. That academics working in Art and Design and Politics feel these now more keenly than those working in Computing or Health Science may suggest that new types of elite are forming in these disciplines. Such elites may be a direct consequence of the increased use of digital technologies and new media, where implementation and usage is determined by centres of power within and outside university bureaucratic structures. Again, a previous relative absence may provoke stronger reactions, and a clearer perception of their existence at the point of emergence. At the same time, a growing diversity of audiences and funding opportunities in traditionally more rigid disciplines such as the Health Sciences may loosen the grip of their extant elites. More flexibility may bring about a lessening in perceived elitism (cf. Whitley, 2000, page 73). Further research would be needed to support such conclusions. Certainly, the new models, methods and technologies shaping the organisation of academia appear to be manifesting themselves in ways which, as Gläser et al. (2011) note, retain discipline specific aspects, even when essentially generic (292).

It is notable however that the two questions where we find the greatest similarity of responses across fields pertain to key current issues around information sharing, audiences and networks. The questions showing insignificant differences across all disciplines (Q5 and 6, with $\mathrm{p}$ values of .193 and .179 respectively) directly address two major modern aspects of academia which have become more pronounced in the years since Whitley constructed his typology:

- The audience that my subject discipline shares its work with is generally varied and diverse 
- It is important to take part in online social networks with academics working in the same subject discipline as myself

The statistical homogeneity on these points lets us interpret the data from an interesting perspective- - that of cultural convergence. Currently common to all disciplines is the expectation of an increased visibility both within disciplinary communities, and beyond them (Nowotny et al., 2002; Whitley, Glaser and Engwall, 2010). Overall, 73.2 percent of respondents agree (51.2) or strongly agree (22) that the audiences they share their work with are varied and diverse. Even in disciplines where a varied audience has not traditionally been an aim (e.g. Health Science), responses are largely positive (71 percent). This may be seen to reflect an increased focus on 'knowledge transfer', wider dissemination, and the engagement of non-traditional audiences. There is now an expectation that audiences for academic work in all disciplines be more diverse, and it appears that most academics feel this is being achieved in their fields. There is also a strong emphasis at present on social networking. When asked however if taking part in online social networks with others in their field is important, only 33 percent agreed, with 35 percent remaining neutral and 9.1 percent agreeing strongly. 22.5 percent disagreed or strongly disagreed. Internet-based channels for academic interactions have been popularised through both external and internal strategies for research and teaching (Weller, 2010; Research Information Network, 2009; DePietro, 2013) yet convictions about the validity of these approaches are less strong among academics in all four disciplines sampled. Interestingly, while the median values in response to Q4 ("Interdisciplinary work is generally important to my subject discipline") were generally positive (4.00 for all groups), those for Q3 - about online social networks and interdisciplinarity—were lower (a neutral 3.00 value for all groups). This may suggest a stronger concern among academics toward the fundamental characteristics and purposes of their disciplines (whether traditional or otherwise) than with the tools and technologies currently being promoted to support them.

\subsection{Directionality and attitudinal strength}

There is a clear trend in directionality (level of agreement or disagreement) across all disciplines, with most respondents agreeing or remaining neutral about the various organisational and social characteristics of their fields, rather than strongly agreeing or disagreeing. Most median values (92.5 percent) are 3.0 or 4.0 rather than 1.0, 2.0 or 5.0. Having explored questionnaire responses in relation to discipline characteristics, it is now worth analysing responses to the semantic differential exercises. These are based 
upon terminology and concepts of new media from multiple fields and can be considered in relation to both discipline, and — as represented by the full dataset—UK academia more generally.

\subsection{Semantic Differentials}

Again, scores on the dependent variable of attitudinal strength (captured as interval data) were not normally distributed; skewness and kurtosis were in evidence in responses to all 12 semantic differential constructs (i.e. adjective pairs). Rather than summing the semantic differential scales, responses to each pair were considered separately, across discipline groups. Non-parametric tests were used. This approach concurs with Sytsma (2002), who contends that "non-normal variables for a semantic differential [when measuring a complex and relatively new stimulus] are not only expected but desired." The complexity of assessing new media, and their novelty in academic systems, means that atypical response patterns are more likely than when studying better-known or more established concepts.

\subsection{Variance between discipline groups}

The distribution of values in response to particular adjective pairs reveals only modest variation by discipline. A Kruskal-Wallis test reveals that in only 4 instances (33.3 percent) can we reject the null hypothesis that the distribution to responses of adjective pairs is the same across categories of discipline (i.e. they do not appear to have been drawn from the same 'population' or group, having asymptotic significance values of .05 or less). Terms with significant variation were Objective-Subjective (sig value of $.003)$, Grounded-Faddish (.006) Social-Isolating (sig value of .008) and Participative-Deliberative (.003). An inspection of illustrative statistics for these pairs suggests that the differences are somewhat minimal, largely explicable because of differences between respondents in Art and Design and those working in Computer Science and/or Politics and International Relations. That value distributions do not differ significantly overall by discipline can be seen in Figure 1 below, where mean responses to each pair of terms, by discipline, are presented (left-hand adjectives are represented here as minus values). 
Figure 1- Distribution of semantic differential values, by discipline

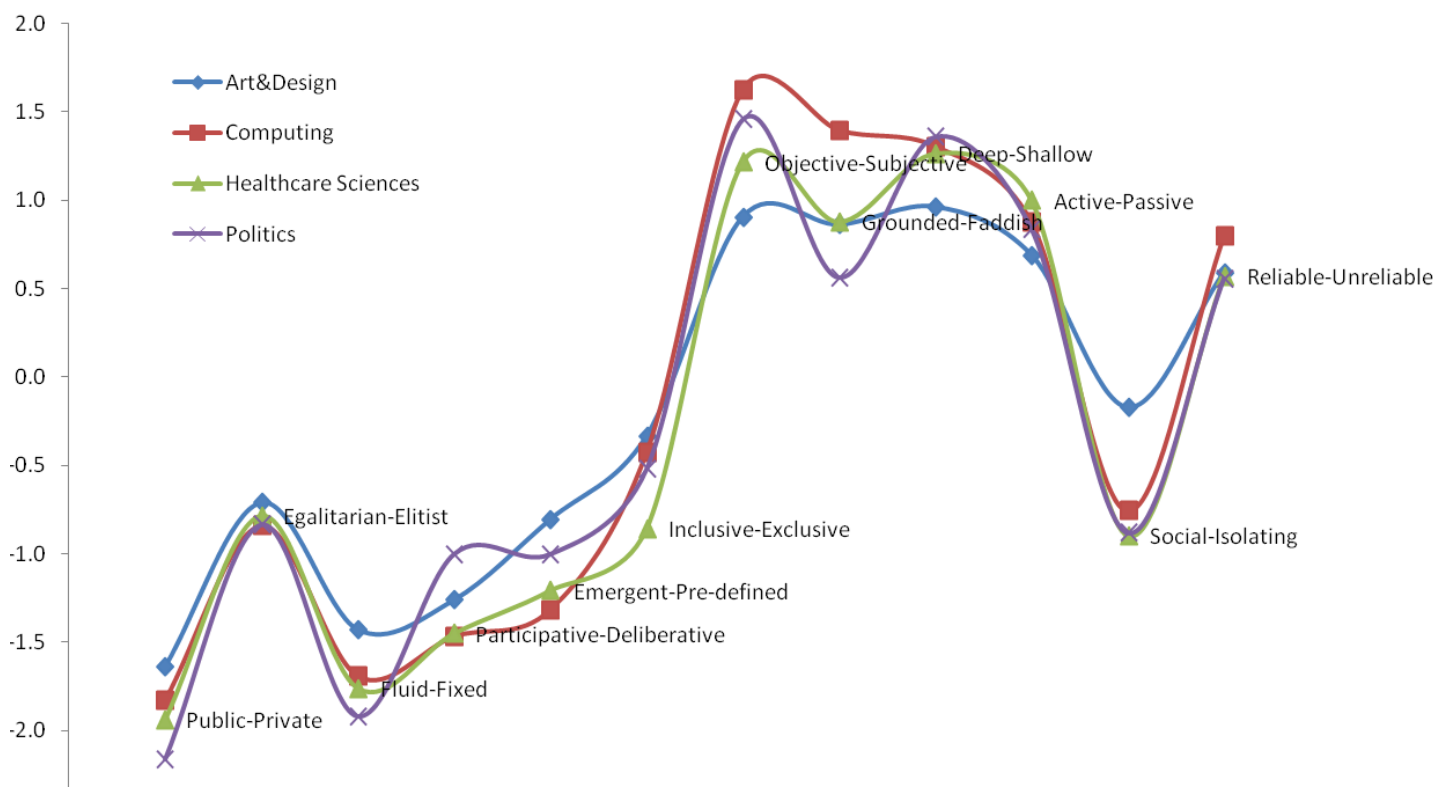

These points of difference might suggest that Art and Design as a discipline is slightly more distinct than others, in terms of how new media are understood and used. Divergence from the means of semantic differential scores for some pairs could indicate a different underlying set of attitudes, assumptions, and interpretations of aspects of both new media and new media discourse, particularly when compared to those based in science and social science. It is reasonable to point out that those working in Art and Design have a very different relationship to, and set of traditions regarding, the use of various types of media and new technology; they are employed for expressive rather than simply instrumental purposes. It is also reasonable to reiterate that difference is nevertheless minimal. Overall, the semantic differential data indicates the absence of strong or clear differences between disciplines (as far as that is expressed in the attitudes of those working in them) when assessing new media. More analysis would be required to further explore the position of Art and Design.

\subsection{Strength and directionality of response}

When asked to position new media in relation to a set of potentially opposing/contrasting concepts, attitudes are in general either moderately strong or neutral rather than 'extreme', both across the whole set and within disciplinary groups. Percentages for each attitudinal scale position are presented in Table 9 below. In 24 percent of responses, the midway 0 point was used, with the moderately strong -2 position being second most frequent ( 17 percent). When we include +2 positions, this gives the 2 positions a total 
of 28 percent. The 3 positions (denoting the most 'extreme' affective or cognitive attitudinal responses) account for only 21 percent of the total combined ( 7 at 3 and 14 at -3 ). The weaker 1 positions account for 24 percent. Two is thus the most common value, followed by 1, 0 then 3 (the remaining 3 percent were left blank).

Table 8 - Medians, by discipline, for responses to questions on discipline characteristics

\begin{tabular}{|c|c|c|c|c|c|c|c|c|c|c|c|}
\hline \multicolumn{2}{|l|}{ Discipline } & Q1 & Q2 & Q3 & $\mathrm{Q}^{4}$ & Q5 & Q6 & Q7 & Q8 & Q9 & Q10 \\
\hline \multirow[t]{2}{*}{ Art and Design } & $\mathrm{N}$ & 56 & 56 & 56 & 56 & 56 & 56 & 56 & 55 & 56 & 52 \\
\hline & Median & 4 & 4 & 3 & 4 & 4 & 3 & 3 & 3 & 4 & 4 \\
\hline \multirow[t]{2}{*}{ Computing } & $\mathrm{N}$ & 76 & 74 & 75 & 75 & 75 & 76 & 75 & 75 & 76 & 75 \\
\hline & Median & 5 & 4 & 3 & 4 & 4 & 3 & 3 & 4 & 4 & 3 \\
\hline \multirow[t]{2}{*}{ Health Sciences } & $\mathrm{N}$ & 52 & 52 & 52 & 52 & 52 & 52 & 52 & 52 & 52 & 52 \\
\hline & Median & 4 & 3 & 3 & 4 & 4 & 3 & 3 & 3 & 4 & 4 \\
\hline \multirow[t]{2}{*}{ Politics } & $\mathrm{N}$ & 25 & 25 & 25 & 25 & 25 & 25 & 25 & 25 & 25 & 24 \\
\hline & Median & 4 & 3 & 2 & 4 & 4 & 3 & 3 & 2 & 4 & 4 \\
\hline \multirow[t]{2}{*}{ Total } & $\mathrm{N}$ & 209 & 207 & 208 & 208 & 208 & 209 & 208 & 207 & 209 & 203 \\
\hline & Median & 4 & 3 & 3 & 4 & 4 & 3 & 3 & 3 & 4 & 4 \\
\hline
\end{tabular}

Table 9 - the number and percentages of values assigned to semantic differential terms, by discipline

\begin{tabular}{r|r|r|r|r|r} 
& Art\&Design & CompSci & \multicolumn{2}{|l|}{$\begin{array}{l}\text { Healthcare } \\
\text { Science }\end{array}$} & $\begin{array}{l}\text { Politics } \\
\text { total values) }\end{array}$ \\
\hline 3 & $43(7)$ & $79(9)$ & $39(6)$ & $20(7)$ & $181(7)$ \\
\hline 2 & $63(10)$ & $122(13)$ & $67(11)$ & $32(11)$ & $284(11)$ \\
\hline 1 & $82(12)$ & $112(12)$ & $81(13)$ & $44(15)$ & $319(13)$ \\
\hline 0 & $216(33)$ & $182(20)$ & $136(22)$ & $61(20)$ & $595(24)$ \\
\hline-1 & $82(12)$ & $125(14)$ & $93(15)$ & $45(15)$ & $345(11)$ \\
\hline-2 & $88(13)$ & $168(18)$ & $112(18)$ & $64(20)$ & $432(17)$ \\
\hline-3 & $69(11)$ & $101(11)$ & $71(11)$ & $27(9)$ & $268(14)$ \\
\hline Blank & $16(2)$ & $23(3)$ & $25(4)$ & $7(2)$ & $71(3)$
\end{tabular}

Across academic disciplines, there is a tendency toward the pragmatic weighing up of what new media mean and what their affordances and characteristics are. A lack of strong or extreme attitudinal associations suggests a potential lack of conviction, and the absence of political and/or ideological 
perspectives, about what they represent and/or actuate ${ }^{4}$. This paucity of extreme values echoes the directionality observed in questions about discipline characteristics, where agreement or neutrality was more common than strong agreement or disagreement. That there are only minimal differences between disciplines makes exploring the semantic differential data independent of discipline groupings worthwhile.

\subsection{Factor Analysis}

Having ascertained this lack of variance, factor analysis - a method of analysis not reliant on sub-groups, and which treats the dataset as a whole to identify patterns and correspondences - was utilised. This allows us to determine "the smallest number of factors that can be used to best represent the interrelationships among the set of variables" (Pallant, 2010, p.183). A Kaiser-Meyer-Olkin test confirmed the adequacy of the sample size for this analysis, with values greater than .6 reported. Bartlett's test of sphericity confirmed suitability for factor analysis, with $\mathrm{p}$ values of less than .05 . Although 4 factors could be identified, only 2 of these featured pairs that loaded highly (above .3), hence a 2 factor solution—with 7 pairs loading highly on one and 4 on a second — was obtained using principal axis factoring, and with coefficients smaller than .3 excluded. Using the MonteCarlo PCA for Parallel Analysis, a 2-factor solution was further confirmed as the most valid and justifiable, based on the generated criterion values. Assuming that factors might be related, as is usual when dealing with psychological constructs (Field, 2011), an oblique (Varimax) rotation with Kaiser Normalization was used. The rotation was converged in 9 iterations.

Items loading highly and similarly on each factor can be grouped together to represent an underlying dimension of attitudes to new media. The first factor (or component) identified deals with the flexibility and activity allowed by the structures of participation and agency which support, or are supported by, new media. To what extent does change and plurality supplant stability? This might be termed 'Flexibility'. The second factor deals with traditional measures of trustworthiness and reliability and might be labelled 'Fitness for Scholarly Purposes'. On this second factor, we observe negative loadings. These are just as strong as positive ones but suggest that low 'levels' of the variable correlate to high levels of the factor. In other words, respondents tended to consider new media as being more shallow, subjective, unreliable and

\footnotetext{
${ }^{4}$ As McCroskey, Prichard and Arnold (1967) note however, "some people may hold "extreme neutral" attitudes $[\ldots]$ and neutral responses to semantic differential scales may have different meanings for different subjects."
} 
faddish than deep, objective, reliable and grounded; and they did so in ways suggestive of a relationship between those perceptions and constructs. Results and loadings are provided in Table 10 below.

Table 10 - The pattern matrix obtained through factor analysis, showing the factor loadings of adjective pairs.

\begin{tabular}{|l|l|l|}
\hline \multicolumn{3}{|c|}{ Pattern Matrix } \\
\hline & \multicolumn{2}{|l|}{ Factor } \\
\cline { 2 - 3 } & 1 & 2 \\
\hline EmergentPredefined & .604 & \\
\hline InclusiveExclusive & .507 & \\
\hline ActivePassive & .454 & \\
\hline FluidFixed & .535 & \\
\hline ParticipativeDeliberative & .543 & \\
\hline PublicPrivate & & \\
\hline SocialIsolating & .465 & \\
\hline EgalitarianElitist & .494 & \\
\hline DeepShallow & & -.739 \\
\hline ObjectiveSubjective & & -.673 \\
\hline ReliableUnreliable & & -.735 \\
\hline GroundedFaddish & & -.518 \\
\hline
\end{tabular}

These two factors suggest a rather practical, logical and generic interpretation by academics of what it is important to consider when assessing new media, particularly salient in educational settings. Positive and negative attitudinal associations or value judgements are apparent and are represented by each one. For instance, researchers, teachers and their students are expected to be active, to participate, and to be nonelitist; these are promoted as positive values for the institution — and of new media, which are largely seen in this light, across disciplines. At the same time, it is fundamental (to most disciplines) that reliability and objectivity are privileged above uncertainty and subjectivity. These traits are, rightly or wrongly, commonly attributed to the content of many new or social media sites and services, hence they are viewed more negatively in relation to these. The solid dimensional underpinnings of the two identified factors may explain the lack of variation between disciplines described above. The only pair of terms which cannot convincingly be associated with a factor is Private-Public; hence this might be retained as a separate pair, 
representing a distinct dimension, in future instruments measuring attitudes to new media. Notably, it is less straightforward to assign 'negative' implications to one term or another in this instance than with others used in the differential charts - for instance, public could imply loss of privacy and an undesired visibility of content, or it could imply participation and positive visibility in the public sphere. This finding suggests, as noted previously in Section 3.2, that more complex constructs and ideas which are less easy to classify as 'good' or 'bad' are not best suited to the semantic differential or to statistical methods of analysis. These can be seen as the two key dimensions underlying academic attitudes toward new media.

\section{Conclusions}

The terms used in the semantic differential exercises were derived from a wide range of literaturesinformation science, political science, philosophy, organisational studies, business, media and cultural studies - thus representing a variety of disciplinary, epistemic and socio-cultural understandings of new media. Respondents across disciplines demonstrated their comprehension of these terms and a willingness to engage with both practical and abstract aspects of new media. It was only in 3 percent of cases that no response was recorded. Academics' responses when asked what 'new media' means to them did not reflect the polemical discourses on new media as a topic of academic research. With the use of these technologies in their work, academics perhaps get a chance to engage with a greater diversity of concepts and theories than would traditionally be associated with one specific field. For instance, computer scientists are most likely to become more aware of philosophical and political aspects of the medium, while artists and designers are likely to become more adept with web technologies and programming languages. This may bring their perspectives and attitudes into closer alignment on issues related to new media, something reinforced by policies and agendas which encourage attitudinal similitude and conformity at the same time as they promote interdisciplinary methods and audience diversity.

The strength of feelings expressed about aspects of new media, especially their political and sociotemporal properties, in both generic and field specific literature was simply not apparent here. Further, some such terms, when included in semantic differentials, tended to compromise scale reliability. Attitudes toward new media appear then not to be anchored by distinct epistemological boundaries or points of differentiation. The strongest finding is that new media appear to be assessed in relation to two practical factors-Flexibility and Fitness for Scholarly Purposes. The first relates to the types of activity and the 
participatory structures enabled or supported by new media. Their perceived flexibility in terms of inclusiveness and individual agency is seen as positive here. The second factor relates to traditional measures of trustworthiness and reliability. Here, new media are more problematic, with academics appearing to find in them a lack of objectivity and a certain 'faddish' quality. They are regarded as instruments or tools. In effect, they are assessed primarily in terms of how suitable they are for the tasks, duties and professionalised imperatives of an academic workplace.

Disciplinary differences remain valuable analytical aids for studying the organisation of academia and its communities. Analysis of respondent data on the nature of disciplines, rather than of new media, revealed statistically significant differences between the four sampled fields, although these differences were modest. Differences were found with regard to issues of novelty, reputation, hierarchy and consensus, demonstrating that discipline characteristics still play an important role in influencing the direction of any given field. However, only modest differentiation was found between disciplinary groups regarding questions of new media and digital technology. This could be seen to challenge narratives of fundamental epistemological distinctions, reflecting the novel interplays brought about by interdisciplinarity, "Mode 2" academia (Nowotny et al. 2002), and post-structural "communicatings" (Dervin, 2003), including altered priorities and models for research and teaching.

The study into academic attitudes toward new media described here suggests that discipline characteristics are not sufficient as an exploratory lens by themselves, particularly because disciplines are subject to change. The cultural and social systems of universities are changing quickly and in complicated ways. There may be an erosion of difference where academic relationships to digital technologies and new media are concerned. New media are now part of the academic toolkit, and a common assessment of their nature and utility seems to have emerged in UK, across otherwise distinct disciplines. This is a plausible consequence of top-down, centralised and 'one size fits all' strategies concerning the use of new media and digital technology for both research and teaching. Devised at the managerial level and in service of government agendas, whether this is positive or negative is a matter of considerable critical debate, and it may be that normative pressures are encouraging conformity and uniformity. The research described here can be located in that context and might contribute usefully to such discussions. In addition this study has demonstrated the use of a flexible, robust methodology for the study of academic attitudes to new media. It 
also finds some evidence to suggest that Art and Design is a more clearly distinct discipline in terms of its relationship to new media, and future research can explore this further. Overall the uniformity of response obtained hints at a flattening out of the critical engagement found in literature on new media and higher education. More research using the exercises and in particular the factors identified here will help us further illuminate these topics. 


\section{Bibliography}

Abbott, A. 2001. Chaos of Disciplines. University of Chicago Press.

Abbas, Y. and Dervin, F., eds. 2009. Digital Technologies of the Self. Newcastle: Cambridge Scholars Publishing:

Agre, P. 2002. Infrastructure and institutional change in the networked university. In Digital Academe, eds.

W.H. Dutton \& B. Loader, pp.152-167. Routledge.

AntonSon, M., and Wendels, C. 2009. Corporate Social Media - Facilitating Better and Faster Change Management. Gothenburg University Publications Electronic Archive. Online at:

http://gupea.ub.gu.se/handle/2077/19571 (Accessed 16th March 2013).

Boeder, P. 2005. Habermas' heritage: The future of the public sphere in the network society. In First Monday 10 (9): $5^{\text {th }}$ September 2005. Online at:

http://firstmonday.org/htbin/cgiwrap/bin/ojs/index.php/fm/article/view/1280/1200 (Accessed 16th March 2013).

Boellstorff, T., B. Nardi, C. Pearce, and T.L. Taylor. 2012. Virtual Ethnography: A Handbook of Method. New Jersey: Princeton University Press.

Bourdieu, P. 1988. Homo Academicus. California: Stanford University Press.

Braun, D. 2011. Governance of universities and scientific innovation. Paper presented at The Sociology of the Social Sciences 1945-2010 Conference, Copenhagen, June 9-10, 2011.

Carter, G.V. and S.J. Arroyo, S.J. 2011. Tubing the Future: Participatory Pedagogy and YouTube U in 2020. In Computers and Composition 28 (4): 292-302.

Castells, M. 1996. The Rise of the Network Society, The Information Age: Economy, Society and Culture Vol. I. Oxford: Blackwell.

Cook, S. D. N. and D. Yanow. 1996. Culture and Organizational Learning. In Organizational Learning, eds. M. D. Cohen and L. Sproull, pp. 430-59. London: Sage. 
Cunningham, J., E. Clements and R. Cunningham. 2012; They Have Come, Why Won't we Build it? On the Digital Future of the Humanities. In Digital Humanities Pedagogy: Practices, Principles and Politics (Google eBook), ed. B.D. Hirsch. Open Book Publishers.

Czerniewicz, L., and C. Brown. 2012. The Habitus of Digital Strangers. In the British Journal of Educational Technology 44 (1): 44-53.

De Lange, M. 2010. Moving Circles: mobile media and playful identities. PhD diss., Erasmus University Rotterdam, Rotterdam. Online at: http://www.bijt.org/wordpress/2010/11/21/download-my-phddissertation-moving-circles/ (accessed 16 ${ }^{\text {th }}$ March 2014).

DePietro, P. 2013. Transforming Education with New Media: Participatory Pedagogy, Interactive Learning, and Web 2.0. Peter Lang Publishing.

Dervin, B. 2003. Verbing communication: Mandate for disciplinary invention. In Sense-Making Methodology reader: Selected writings of Brenda Dervin eds. B. Dervin and L. Foreman-Wernet with E. Lauterbach, pp. 101-110. Cresskill, New Jersey: Hampton Press.

Dutton, W. H., and B.D. Loader, eds. 2002. Digital Academe: New Media and Institutions in Higher Education and Learning. Taylor and Francis/Routledge.

Engeström, Y., R. Miettinen, and R.L. Punamäki-Gitai eds.1999. Perspectives on activity theory. Cambridge: Cambridge University Press.

Engwall, L. 1995. Management Research: A Fragmented Adhocracy? Scandinavian Journal of Management, 11 (3): 225-235.

Engwall, L. and R. Danell, R. 2011. The Fragmented Adhocracy revisited: Movements in Management Studies. Paper presented at The Sociology of the Social Sciences 1945-2010 conference, Copenhagen, June 9-10, 2011.

Field, A. 2011. Factor Analysis/PCA. Online at: https://www.youtube.com/watch?v=UWP9OEoaNnE (Accessed 16 $6^{\text {th }}$ March 2014).

Fleck, L. 1936.. The Problem of Epistemology. Cognition and Fact - Materials on Ludwik Fleck, R.S. Cohen and T Schnelle eds. 1986. Dordrecht: Reidel. 
Forgas, J.P., J. Cooper, J., and W.D. Crano. 2010. The Psychology of Attitudes and Attitude Change. New York: Taylor and Francis.

Foucault, M. 1966. The Order of Things: An Archaeology of the Human Sciences. London and New York: Routledge.

Fry, J., and S. Talja. 2007. The Intellectual and Social Organization of Academic Fields and the Shaping of Digital Resources. Journal of Information Science. 33(2): 115-133.

Gläser, J., S. Lange, G. Laudel, U. Schimank. 2010. The Limits of Universality: How Field-Specific Epistemic Conditions Affect Authority Relations and their Consequences. In Reconfiguring Knowledge Production. Changing Authority Relationships in the Sciences and their Consequences for Intellectual Innovation, eds. R. Whitley, J. Gläser and L. Engwall, pp.291-325.Oxford University Press.

Goode, L. 2010. New media and Democracy. In New Zealand Government and Politics ( $5^{\text {th }}$ edition), ed. R. Miller, pp.431-443. Oxford University Press.

Ghareeb, E. 2000. New Media and the Information Revolution in the Arab World: An Assessment. The Middle East Journal 54 (3): pp.395-418.

Goggins, S. P., J. Laffey and M. Gallagher. 2011. Completely online group formation and development: small groups as socio-technical systems. Information Technology and People 24 (2): 104-133.

Graham, P. 2006. Hypercapitalism: New Media, Language, and Social Perceptions of Value. Peter Lang.

Guyette, R. W., and C. Piotrowski. 2009. Attitudes of corporate tax students toward general business concepts. Organization Development Journal, 27(1): 65-70.

Guyette, R.W., and C. Piotrowski. 2010. The Case for the Semantic Differential in Organizational and Business Research. In The Journal for Instructional Psychology. December 2010.

Higher Education Statistics Agency. 2013a. All staff in UK HE institutions by activity, mode of employment and gender 2011/12. Table 1. Online at: http://www.hesa.ac.uk/component/option,com_pubs/Itemid,286/task,show_year/pubId,1717/versionId,27/y earId,282/ (Accessed 16 ${ }^{\text {th }}$ March 2014). 
Higher Education Statistics Agency. 2013b. Staff in Higher Education Institutions 2012/13. Extracts online at: http://www.hesa.ac.uk/content/view/3128/393/ (Accessed 16 ${ }^{\text {th }}$ March 2014).

Heimeriks, G.J., P. van den Besselaar and K. Frenken. 2008. Digital disciplinary differences: An analysis of computer-mediated science and 'Mode 2' knowledge production. Research Policy 37 (9) pp. 16021615.

Heise, D.R. 1970. Chapter 14. In Attitude Measurement, eds. G.F. Summers, pp.235-253. Chicago: Rand McNally.

Hine, C. 2006. Infrastructures for Knowledge Production: Understanding eScience. Idea Group Inc: London.

Hirsch, B.D., ed. Digital Humanities Pedagogy: Practices, Principles and Politics (Google eBook). Open Book Publishers, 2012.

Holsanova, J. 2010. Cognition, multimodal interaction and new media. Online at: http://www.fil.lu.se/hommageawlodek/site/papper/HolsanovaJana.pdf (Accessed 16th March 2014).

Horst, H. A., and D. Miller, eds. 2012. Digital Anthropology. New York: Berg Publishers.

Huhtamo, E., and J. Parikka eds. 2011. Media Archaeology: Approaches, Applications, and Implications. University of California Press.

Knudsen, C. 2011. The comparative study of Intellectual and Social Structures in the Social Sciences: A Review of Perspectives from Organization Studies. Paper presented at "The Sociology of the Social Sciences 1945-2010” Conference, Copenhagen June 9-10, 2011.

Key, J.P. 2007. Research Design in Occupational Education. Other Data Gathering Tools for a Research Investigation. Oklahoma State University. Online at: http://www.okstate.edu/ag/agedcm4h/academic/aged5980a/5980/newpage17.htm (Accessed 16th March 2014).

Khondker, H.H. 2011. Role of the new media in the Arab Spring. Globalizations 8 (5): 675-679.

Kress, G. 2005. Gains and losses: New forms of texts, knowledge, and learning. Computers and Composition 22 (1): 5-22 
Kuhn, T.S. 1996. The Structure of Scientific Revolutions. Chicago: University of Chicago Press.

Lanham, D. 1993. The Electronic Word: Democracy, Technology, and the Arts. Chicago: The University of Chicago Press.

Lattuca, L.R. 2001. Creating Interdisciplinarity: Interdisciplinary research and teaching among college and university faculty. Nashville: Vanderbilt University Press.

Laurel, B. 1993. Computers as Theatre. Addison Wesley Longman Inc.

Lave, J. and E. Wenger. 1991. Situated Learning. Legitimate Peripheral Participation. Cambridge, Cambridge University Press.

Lee, S. J., J.H. Kim and D. Rosen. 2009. A semantic network and categorical content analysis of Internet and online media research. Open Communication Journal 3: 15-28.

McCroskey, J.C., S. V. O. Pritchard, and W.E. Arnold. 1967. Attitude Intensity and the Neutral Point on Semantic Differential Scales. American Association for Public Opinion Research, 31(4): 642-645. Oxford: Oxford University Press.

McLuhan, M. 1964. Understanding Media: The Extensions of Man. New York: McGraw-Hill..

Manovich, L. 2001. The Language of new media. Massachusetts: MIT Press.

Marx, K. 1977. A Contribution to the Critique of Political Economy. With some notes by R. Rojas.

Moscow: Progress Publishers. Online at: http://www.marxists.org/archive/marx/works/1859/critique-poleconomy/preface.htm (Accessed 20th March 2014).

Merrill, N. 2011. Social Media for Social Research: Applications for Higher Education Communications. Higher Education Administration with Social Media (Cutting-edge Technologies in Higher Education) 2, eds. L.A. Wankel and C. Wankel, pp.25-48. Emerald Group Publishing Limited.

Miller, T. 2001. Disciplinary identifications/public identities: A response to Mailloux, Leff, and Keith. Rhetoric Society Quarterly, 31 (3): 105-117.

Murray, J. H. 1997. Hamlet on the Holodeck. The Future of Narrative in Cyberspace. Massachusetts: MIT Press. 
Milin, P. and S. Zdravkovic (2011). Semantic representations in 3D perceptual space. iPercpetion Vol. 2. Online at: http://i-perception.perceptionweb.com/journal/I/article/ic297 (Accessed 16th March 2014).

Nardi, B.A. and V.L. O'Day. 1999. Information Ecologies: Using Technology with Heart. Massachusetts: MIT Press.

Nowotny, H., P. Scott and M. Gibbons. 2002. Re-Thinking Science. Knowledge and the Public in an Age of Uncertainty. Cambridge: Polity Press.

Nystrand, M. 1982. What Writers Know: The Language, Process, and Structure of Written Discourse. New York: Academic.

Nystrand, M. 2001. Distinguishing formative and receptive contexts in the disciplinary formation of composition studies: A response to Mailloux. Rhetoric Society Quarterly, 31 (3): 92-104.

Ornek, F. Cultural Influence on Attitude towards Science. In Attitude Research in Science Education: Classic and Contemporary Measurements, eds. I.M. Saleh and M.S. Khine, pp.241-261. North Carolina: Information Age Publishing.

Osgood, C.E., C.J. Suci and P.H. Tannenbaum. 1957. The measurement of meaning. Urbana, IL: University of Illinois Press.

Pallant, J. 2010. SPSS Survival Manual. $4^{\text {th }}$ Edition. Open University Press.

Papacharissi, Z. 2008. Uses and Gratifications. In An Integrated Approach to Communication Theory and Research, eds. M. Salwen and D. Stacks. Routledge.

Research Information Network. 2010. If you build it will they come? How researchers perceive and use Web 2.0. July 2010. Research Information Network.

Rice, J. and M. O'Gorman. 2008. New media/new methods: the academic turn from literacy to electracy. West Lafayette: Parlor Press.

Rogers, D. L. 2000. A paradigm shift: Technology integration for higher education in the new millennium. Educational Technology Review, 1(13), 19-33.

Rogers, K. 2008. Participatory Democracy, Science and Technology. Palgrave Macmillan: London. 
Schaefer, M. and M. Rotte, 2010. Combining a semantic differential with fMRI to investigate brands as cultural symbols. Social Cognition and Affective Neuroscience, 5 (2-3): 274-281.

Scharf, E. S. 1971. The Use of the Semantic Differential in Measuring Attitudes of Elementary School Children Toward Mathematics. School Science and Mathematics 71: 641-649. doi: 10.1111/j.19498594.1971.tb13773.x (Accessed 16 $6^{\text {th }}$ March 2014).

Scholz, T. 2005. The Participatory Challenge. In Curating Immateriality. DATA browser 3, ed. J. Krysa, pp.194-122. New York: Autonomedia.

Smith, M.A. and P. Kollock. 1999. Communities in cyberspace. New York, New York: Routledge.

Sytsma R. 2002. Factor Analytic Results from a Semantic Differential on the Construct Optimism. Neag Centre for Gifted Education and Talent Development: University of Connecticut. (Accessed $18^{\text {th }}$ March 2014).

Sywak, M. 1990. A Thirteen-Year Study of Library School Student Attitudes. Journal of Education for Library and Information Science. 30 (4): 285-297.

Trowler, P. 2009. Beyond epistemological essentialism: academic tribes in the twenty-first century. In The University and its Disciplines. Teaching and Learning Within and Beyond Disciplinary Boundaries, ed. C. Kreber, pp.181-195. London: Routledge.

Turkle, S. 2011. Alone Together: Why We Expect More from Technology and Less from Each Other. New York: Basic Books.

Weller, M. 2011. The Digital Scholar: How Technology Is Transforming Scholarly Practice. Basingstoke: Bloomsbury Academic.

Whitley, R. 2000. The intellectual and social organization of the sciences. $2^{\text {nd }}$ edition. Oxford: Clarendon Press.

Whitley, R., J. Gläser, J. and L. Engwall. 2010. Reconfiguring Knowledge Production. Changing Authority Relationships in the Sciences and their Consequences for Intellectual Innovation. Oxford University Press. Wysocki, A.F., E.J. Johndan, C. Selfe and G. Sirc. 2004. Writing New Media: Theory and applications for expanding the teaching of composition. Logan, UT: Utah State University Press. 